\title{
PENERAPAN METODE SERVICE QUALITY (SERVQUAL) UNTUK PENINGKATAN KUALITAS PELAYANAN PELANGGAN
}

\author{
Yandra Prananda, Dyah Rachmawati Lucitasari dan M. Shodiq Abdul Khannan \\ Prodi Teknik Industri \\ Jurusan Teknik Industri, Fakultas Teknik Industri \\ Universitas Pembangunan Nasional "Veteran" Yogyakarta \\ Jl. Babarsari 2 Tambakbayan, Yogyakarta, 55281 \\ Telp. (0274) 485363 Fak : (0274) 486256 \\ email : dlucitasari@yahoo.co.id, shodiq@upnyk.ac.id
}

\begin{abstract}
ABSTRAK
Kualitas layanan menjadi tolak ukur utama perusahaan di industri perhotelan. Kualitas layanan yang baik akan membuat hotel tersebut menjadi kompetitif dan akan menjadi pilihan konsumen ketika mencari tempat untuk menginap. Hotel yang menjadi objek penelitian pada skripsi ini adalah Hotel Vidi 2 yang merupakan hotel dengan klasifikasi hotel melati yang berkapasitas 65 kamar yang berlokasi di Jl. Kaliurang km 5, kabupaten Sleman, Yogyakarta. Dari data keuangan Hotel Vidi 2 dalam 3 bulan terakhir yaitu bulan Juli, Agustus, dan September 2015 terjadi penurunan dengan rata-rata 19\%, hal tersebut terjadi akibat beberapa sebab salah satunya karena kualitas pelayanan yang kurang baik dari Hotel Vidi 2, sehingga mengakibatkan pelanggan beralih ke pesaing lainnya, dan pendapatan hotel menjadi menurun.

Dalam penelitian ini kualitas layanan yang menjadi pokok permasalahan, diukur dengan Service Quality (SERVQUAL) dimana di dalam metode tersebut membahas tentang dimensi-dimensi kualitas yakni: Tangible, Reliability, Responsiveness, Assurance dan Empathy. Tahapan awal yang dilakukan dalam penelitian ini dengan melakukan analisa terlebih dahulu dari kekurangan yang terdapat didalam hotel terutama pada bidang kualitas layanan. Setelah analisa permasalahan yang terdapat pada hotel, maka peneliti melakukan penyebaran kuisioner terhadap konsumen sehingga permasalahan kualitas pelayanan dapat diketahui subjeknya.

Hasil penelitian dari setiap dimensi pada SERVQUAL yakni Tangible, Reliability, Responsiveness, Assurance, dan Emphaty. Menunjukkan bahwa dimensi bukti fisik (Tangible) merupakan dimensi yang memiliki nilai kualitas terkecil, sedangkan nilai kualitas terbesar terdapat pada dimensi jaminan (Assurance).
\end{abstract}

Kata Kunci: kualitas layanan, SERVQUAL, tangible, responsiveness, reliability, assurance, dan emphaty

\section{PENDAHULUAN}

Kualitas layanan merupakan salah satu kebutuhan bagi industri dalam beberapa tahun terakhir terlihat bahwa pembangunan di semua sektor industri cukup meningkat, salah satunya industri yang berorientasi pada jasa dan pelayanan untuk konsumen seperti industri perhotelan, hal ini tidak terlepas dari permintaan pasar yang juga meningkat setiap tahunnya akan industri perhotelan. Dari sisi tingkat kepentingan, industri hotel memang tidak terlalu menarik untuk beberapa konsumen yang tidak membutuhkan, namun akan menjadi tolak ukur yang besar bagi konsumen yang membutuhkan hotel sebagai pendukung bagi kelangsungan bisnis ataupun pekerjaan mereka.

Hotel Vidi 2 yang merupakan hotel dengan klasifikasi hotel melati yang berkapasitas 65 kamar yang berlokasi di Jl. Kaliurang km 5, kabupaten Sleman, Yogyakarta. Pengunjung Hotel Vidi 2 terdiri dari berbagai lapisan masyarakat mulai dari pengusaha, pegawai negeri, swasta, dan mahasiswa. Dari data keuangan Hotel Vidi 2 dalam 3 bulan terakhir yaitu bulan Juli, Agustus, dan September 2015 terjadi penurunan dengan rata-rata $19 \%$, hal tersebut terjadi akibat beberapa sebab salah satunya karena kualitas pelayanan yang kurang baik dari Hotel Vidi 2, sehingga mengakibatkan pelanggan beralih ke pesaing lain, dan pendapatan hotel menjadi menurun.

Penelitian ini berfokus pada peningkatan layanan dengan menggunakan metode Servqual, dimana di dalam metode tersebut membahas tentang dimensi-dimensi kualitas yakni: Tangible, Reliability, Responsiveness, Assurance dan Empathy.

\section{LANDASAN TEORI}

2.1 Kualitas

2.1.1 Pengertian kualitas

Kualitas adalah sebuah kata yang bagi penyedia jasa merupakan sesuatu yang harus dikerjakan dengan baik. Menurut American 
Society For Quality Control (Kotler,1994) kualitas adalah keseluruhan ciri serta sifat dari suatu produk atau pelayanan yang berpengaruh pada kemampuannya untuk memuaskan kebutuhan yang dinyatakan atau yang tersirat.

\subsubsection{Kualitas jasa}

Kualitas jasa menurut Tjiptono (2000), merupakan penyesuaian terhadap perincianperincian dimana kualitas ini dipandang sebagai derajat keunggulan yang ingin dicapai, dilakukannya kontrol terus menerus dalam mencapai keunggulan tersebut dalam rangkaian memenuhi kebutuhan pengguna jasa.

\subsubsection{Kualitas pelayanan}

Menurut Parasuraman (1993) kualitas pelayanan (service quality) didefenisikan sebagai sesuatu yang terdapat perbedaan antara kenyataan dan harapan para pelanggan atas layanan yang mereka peroleh.

\subsection{Kepuasan Pelanggan}

Kepuasan pelanggan didefinisikan sebagai respons pelanggan terhadap ketidak sesuaian antara tingkat kepentingan sebelumnya dan kinerja actual yang dirasakan setelah pemakaian. Kepuasan pelanggan, selain dipengaruhi oleh kualitas jasa, juga ditentukan oleh kualitas produk, harga, dan faktor-faktor yang bersifat pribadi serta yang bersifat situasi sesaat (Rangkuti, 2002).

\subsection{Metode Service Quality (Servqual)}

Metode Servqual adalah metode yang sering digunakan untuk mengukur kualitas pelayanan. Pengukuran mutu untuk produk fisik tidak sama dengan industri jasa. Analisis diawali dengan sebuah kuisioner yang disebarkan kepada konsumen, setiap item pertanyaan memiliki dua jawaban dalam skala (Likert), yaitu apakah menurut nasabah hal tersebut penting untuk dilakukan atau dilaksanakan dan bagaimana kinerjanya, baik atau tidak baik. Misalnya contoh pertanyaan sebagai berikut:

Karyawan ramah terhadap tamu hotel vidi :

Apakah menurut anda : Tidak penting $(1 \rightarrow 5)$ Penting

Bagaimana kinerjanya $\quad$ :Tidak penting $(1 \rightarrow 5)$ Baik

Setelah data dari kuisioner didapat maka dihitung rata-rata tiap pertanyaan dari seluruh responden, dengan menggunakan persamaan (Supranto, 2001):

$$
\bar{X}=\frac{\sum_{i=1}^{n} x i}{n}
$$

$$
\bar{Y}=\frac{\sum_{i=1}^{n} Y i}{n}
$$

Keterangan:

$\bar{X}$ : Skor rata-rata tingkat kepuasan/realita.

$\bar{Y}$ : Skor rata-rata tingkat kepentingan/ekspektasi $n:$ Jumlah responden.

\section{METODOLOGI PENELITIAN \\ 3.1 Objek Penelitian}

Penelitian ini dilakukan pada tanggal 06 Juni s.d 06 Juli 2015 di Hotel Vidi 2 Yogyakarta, yang merupakan salah satu industri yang bergerak di bidang pelayanan jasa. Objek penelitian ini adalah pelanggan di Hotel Vidi 2, Yogyakarta.

\subsection{Langkah-langkah Pengumpulan \\ Data}

Dalam penelitian ini, data yang dikumpulkan berupa data primer dan data sekunder yang bersifat kualitatif dan kuantitatif.

\section{Data Primer}

Data primer merupakan data yang diperoleh langsung dari objek yang akan diteliti yang berhubungan atau berkaitan dengan pelanggan di Hotel Vidi 2. Langkah pertama yang dilakukan adalah observasi untuk mengumpulkan data dengan cara melakukan pengamatan dan peninjauan secara langsung terhadap objek yang diteliti. Selanjutnya melakukan wawancara dengan konsumen hotel dan berdiskusi dengan pihak hotel untuk mendapatkan atribut layanan sesuai dengan apa yang dibutuhkan konsumen hotel.

\section{Data Sekunder}

Data sekunder merupakan data yang didapatkan dengan mempelajari literature yang berhubungan dengan penelitian dan dokumendokumen yang ada di Hotel Vidi 2. Data-data ini berisi tentang petunjuk dalam pelaksanaan penelitian dan semua informasi yang berguna dalam penyusunan laporan..

\subsection{Pengolahan Data}

1. Uji validitas data

Dilakukan untuk menguji apakah tiap atribut-atribut pertanyaan telah mengungkapkan faktor yang ingin diselidiki sesuai dengan kondisi populasinya.

\section{Uji reliabilitas data \\ Reliabilitas data dilakukan untuk menguji kehandalan suatu kuisioner pontuk cukup dapat dipercaya sebagailatadpengut}


data. Angka koefisien reliabilitas berkisarantara 0.00 hingga 1.00. Butir kuisioner dinyatakan reliable jika memberikan alpha $>0.60$.

\subsection{Menerapkan metode service quality (servqual)}

Perancangan kualitas pelayanan dilakukan dengan menggunakan pendekatan Service Quality (Servqual) sesuai dengan kebutuhan dan keinginan tamu/pelanggan.

\section{HASIL DAN PEMBAHASAN}

Data-data yang telah terkumpul dilakukan uji validitas, untuk uji validitasi ini dihitung dengan menggunakan bantuan perangkat lunak Statistical Product and Service Solutions (SPSS) versi 16 dengan hasil yang dapat dilihat pada Lampiran E. Hasil dari perhitungan SPSS akan diperoleh nilai $r$ untuk masing-masing butir pertanyaan yang kemudian akan dibandingkan dengan nilai $r$ pada tabel untuk degree of freedom $(\mathrm{df})=\mathrm{n}-2$, jumlah sampel minimal $(\mathrm{n})=50$. Besarnya $d f$ dihitung 50-2 $=48, r$ tabel $=0,284$. Jika $r$ tabel $<\mathrm{r}$ hitung maka butir-butir pertanyaan kuisioner yang diajukan kepada pelanggan dinyatakan valid.

Tabel 4.1 Hasil uji validitas realita dan ekspektasi.

\begin{tabular}{|c|c|c|c|c|}
\hline No & $\begin{array}{c}\boldsymbol{r} \\
\text { tabel }\end{array}$ & Realita & Ekspektasi & $\begin{array}{c}\text { Valid/ } \\
\text { tidak }\end{array}$ \\
\hline 1 & 0,284 & 0,490 & 0,434 & Valid \\
\hline 2 & 0,284 & 0,383 & 0,465 & Valid \\
\hline 3 & 0,284 & 0,443 & 0,517 & Valid \\
\hline 4 & 0,284 & 0,568 & 0,723 & Valid \\
\hline
\end{tabular}

\begin{tabular}{|c|c|c|c|c|}
\hline No & $\begin{array}{c}\boldsymbol{r} \\
\text { tabel }\end{array}$ & Realita & Ekspektasi & $\begin{array}{l}\text { Valid/ } \\
\text { tidak }\end{array}$ \\
\hline 5 & 0,284 & 0,597 & 0,388 & Valid \\
\hline 6 & 0,284 & 0,580 & 0,663 & Valid \\
\hline 7 & 0,284 & 0,541 & 0,291 & Valid \\
\hline 8 & 0,284 & 0,325 & 0,416 & Valid \\
\hline 9 & 0,284 & 0,572 & 0,621 & Valid \\
\hline 10 & 0,284 & 0,426 & 0,538 & Valid \\
\hline 11 & 0,284 & 0,399 & 0,373 & Valid \\
\hline 12 & 0,284 & 0,422 & 0,715 & Valid \\
\hline 13 & 0,284 & 0,391 & 0,404 & Valid \\
\hline 14 & 0,284 & 0,550 & 0,568 & Valid \\
\hline 15 & 0,284 & 0,362 & 0,549 & Valid \\
\hline
\end{tabular}

\subsubsection{Uji reliabilitas data}

Uji reliabilitas dilakukan dengan menghitung nilai alpha crobach pada perangkat lunak SPSS versi 16 . Data dapat dinyatakan reliable apabila $\alpha$ lebih besar dari 0,6 .

Tabel 4.2 Hasil uji reliabilitas realita dan ekspektasi

\begin{tabular}{|l|r|r|}
\multicolumn{2}{c}{} & ekspektasi \\
\cline { 2 - 3 } \multicolumn{1}{c|}{} & Realita & Ekspektasi \\
\hline Nilai Cronbach a & 0,600 & 0,600 \\
\hline Koef $a$ & 0,819 & 0,864 \\
\hline
\end{tabular}

4.2.3 Menerapkan metode service quality (servqual)

Nilai kepentingan, kepuasan, dan gap dapat dilihat pada Tabel 4.3

Tabel 4.3. Kepentingan, Kepuasan, dan Gap Tiap Atribut

\begin{tabular}{|c|c|c|c|c|}
\hline No & Atribut & Kepentingan & Kepuasan & Gap \\
\hline \multicolumn{5}{|c|}{ Dimensi Bukti Fisik (Tangibles) } \\
\hline 1 & Lokasi hotel strategis & 4,14 & 3,66 & $-0,48$ \\
\hline 2 & Keadaan kamar hotel (bersih, nyaman, luas) & 4,02 & 3,20 & $-0,82$ \\
\hline 3 & Toilet kamar hotel (bersih, nyaman, wangi) & 3,86 & 3,16 & $-0,7$ \\
\hline 4 & $\begin{array}{l}\text { Fasilitas yang ada di kamar hotel (TV, AC, kasur, } \\
\text { selimut, WIFI) }\end{array}$ & 3,72 & 3,48 & $-0,24$ \\
\hline 5 & Tempat parkir luas & 3,74 & 2,30 & $-1,44$ \\
\hline 6 & $\begin{array}{l}\text { Penampilan karyawan (rapi, sopan, seragam, } \\
\text { formal) }\end{array}$ & 3,76 & 3,34 & $-0,42$ \\
\hline 7 & Penampilan manager (rapi, sopan) & 3,46 & 3,08 & $-0,38$ \\
\hline 8 & Tersedia kendaraan di hotel (mobil rental) & 3,70 & 2,30 & $-1,4$ \\
\hline \multicolumn{2}{|r|}{ Mean } & 3,8 & 3,065 & $-0,735$ \\
\hline 9 & Ketepatan waktu pelayanan & 4,04 & 3,34 & $-0,7$ \\
\hline \multicolumn{2}{|r|}{ Mean } & 4,04 & 3,34 & $-0,7$ \\
\hline \multicolumn{5}{|c|}{ Dimensi Daya Tanggap (Responssivness) } \\
\hline 10 & Kecepatan karyawan dalam melayani pelanggan & 4,10 & 3,52 & $-0,58$ \\
\hline 11 & Manager mengatasi keluhan pelanggan dengan baik & 3,76 & 3,16 & \\
\hline
\end{tabular}




\begin{tabular}{|c|c|c|c|c|}
\hline No & Atribut & Kepentingan & Kepuasan & Gap \\
\hline & Mean & 3,93 & 3,34 & $-0,59$ \\
\hline \multicolumn{5}{|c|}{ Dimensi Jaminan (Assurance) } \\
\hline 12 & Adanya pihak keamanan/security (satpam) & 3,86 & 3,72 & $-0,14$ \\
\hline & Mean & 3,86 & 3,72 & $-0,14$ \\
\hline \multicolumn{5}{|c|}{ Dimensi Empati (Emphaty) } \\
\hline 13 & Keramahan karyawan terhadap pelanggan & 4,24 & 3,46 & $-0,78$ \\
\hline 14 & $\begin{array}{l}\text { Ketersediaan waktu karyawan dalam mendengar } \\
\text { keluhan pelanggan }\end{array}$ & 4,04 & 3,32 & $-0,72$ \\
\hline 15 & Karyawan dapat berkomunikasi dengan baik & 3,90 & 3,52 & $-0,38$ \\
\hline \multicolumn{2}{|r|}{ Mean } & 4,12 & 3,43 & $-0,687$ \\
\hline
\end{tabular}

\section{Kualitas layanan tiap dimensi}

Dari dimensi bukti fisik (tangible), kehandalan (reliability), daya tanggap (responsiveness), jaminan (assurance), dan empati (emphaty) kemudian diambil mean dan gap tiap dimensi. Untuk menganalisis kualitas layanan yang telah diberikan pihak perusahaan maka digunakan rumus (Besterfield, 1998) dalam (Dorothea, 2003) yaitu:
Kualitas Layanan $(Q)$

$$
=\frac{\text { Penilaian }(\text { Kepuasan })}{\text { Harapan }(\text { Kepentingan })}
$$

Jika $\mathrm{Q} \geq 1$, maka kualitas pelayanan dikatakan baik.

Menurut Parasuraman (1998), metode Servqual digolongkan ke dalam lima dimensi yakni, Tangibles, Reliability, Responsiveness, Assurance, Emphaty. Kualitas layanan tiap dimensi dapat dilihat pada Tabel 4.4.

Tabel 4.4 Kualitas Pelayanan Tiap Dimensi

\begin{tabular}{|c|l|c|c|c|c|}
\hline No & \multicolumn{1}{|c|}{ Dimensi } & Kepentingan $(\mathrm{H})$ & $\begin{array}{c}\text { Kepuasan } \\
(\mathrm{P})\end{array}$ & Gap & $\begin{array}{c}\text { Kualitas } \\
\text { Layanan }(\mathrm{Q})\end{array}$ \\
\hline 1 & Bukti Fisik (Tangibles) & 3,8 & 3,065 & $-0,735$ & 0,806 \\
\hline 2 & Kehandalan (Reliability) & 4,04 & 3,34 & $-0,7$ & 0,826 \\
\hline 3 & Daya Tanggap (Responssivness) & 3,93 & 3,34 & $-0,59$ & 0,850 \\
\hline 4 & Jaminan (Assurance) & 3,86 & 3,72 & $-0,14$ & 0,964 \\
\hline 5 & Empati (Emphaty) & 4,06 & 3,43 & $-0,687$ & 0,833 \\
\hline \multicolumn{2}{|c|}{ Mean } & 3,95 & 3,38 & $-0,57$ & 0,857 \\
\hline
\end{tabular}

\subsubsection{Diagram Kartesius}

Rata-rata kepentingan dan kepuasan semua atribut dapat dilihat pada Tabel 4.5

Tabel 4.5 Rata-rata Kepentingan dan Kepuasan Semua Atribut

\begin{tabular}{|c|l|c|c|}
\hline No & \multicolumn{1}{|c|}{ Atribut } & $\begin{array}{c}\text { Kepentingan/ } \\
\text { Harapan }\end{array}$ & $\begin{array}{c}\text { Kepuasan/ } \\
\text { Persepsi }\end{array}$ \\
\hline 1. & Lokasi hotel strategis & 4,14 & 3,66 \\
\hline 2. & Keadaan kamar hotel (bersih, nyaman, luas) & 4,02 & 3,2 \\
\hline 3. & Toilet kamar hotel (bersih, nyaman, wangi) & 3,86 & 3,16 \\
\hline 4. & Fasilitas yang ada di kamar hotel (TV, AC, kasur, selimut, WIFI) & 3,72 & 3,48 \\
\hline 5. & Tempat parkir luas & 3,74 & 2,3 \\
\hline 6. & Penampilan karyawan (rapi, sopan, seragam, formal) & 3,76 & 3,34 \\
\hline 7. & Penampilan manager (rapi, sopan) & 3,46 & 3,08 \\
\hline 8. & Tersedia kendaraan di hotel (mobil rental) & 3,7 & 2,3 \\
\hline 9. & Ketepatan waktu pelayanan & 4,04 & 3,34 \\
\hline 10. & Kecepatan karyawan dalam melayani pelanggan & 4,1 & 3,52 \\
\hline 11. & Manager mengatasi keluhan pelanggan dengan baik & 3,76 & 3,16 \\
\hline 12. & Adanya pihak keamanan/security (satpam) & 3,86 & 3,72 \\
\hline 13. & Keramahan karyawan terhadap pelanggan & 4,24 & 3,46 \\
\hline 14. & Ketersediaan waktu karyawan dalam mendengar keluhan & 4,04 & 3,32 \\
\hline 15. & Kelanggan & 3,9 & 3,52 \\
\hline
\end{tabular}




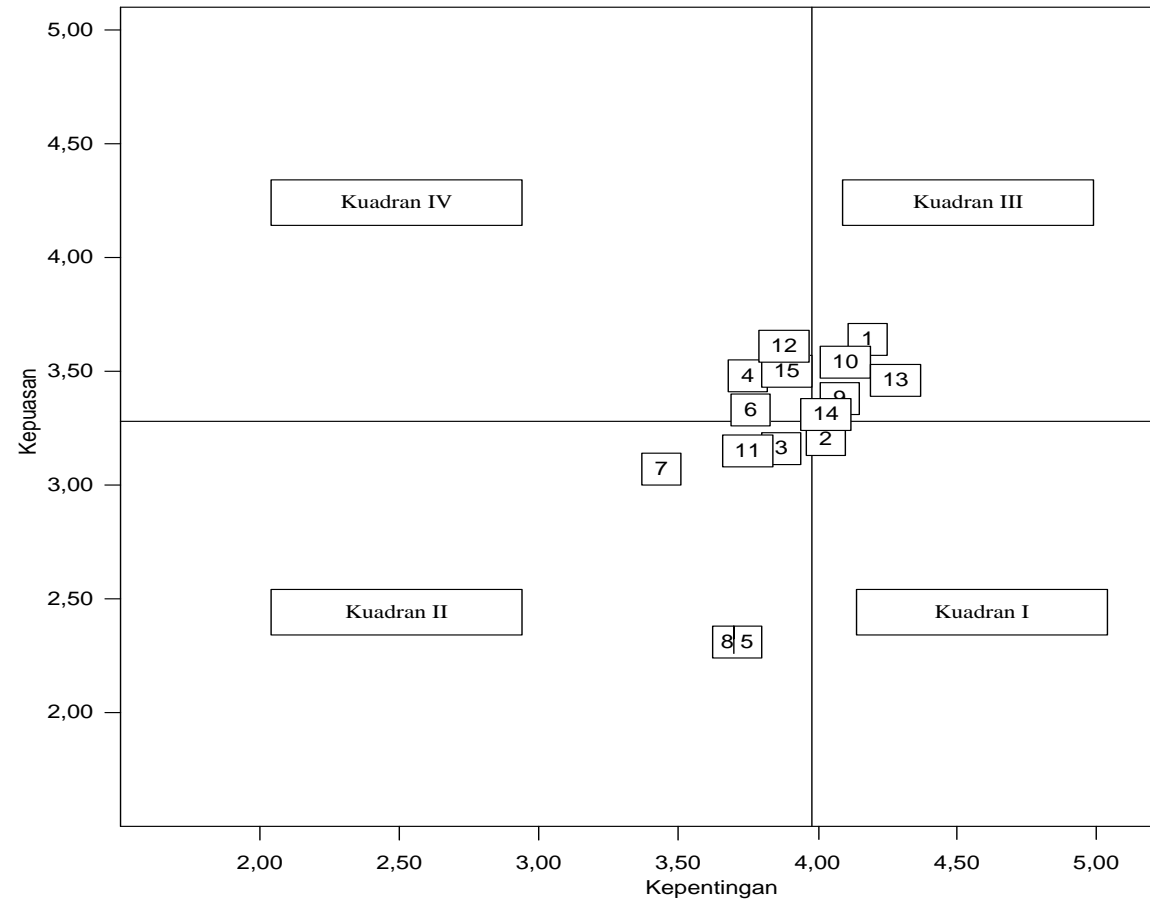

Keterangan :

Gambar 4.1 Diagram Kartesius Semua Atribut

\section{Kuadran I}

Pihak produsen harus berhati-hati karena tingkat keinginan akan tingkat importance dari konsumen sangatlah tinggi dan produsen harus berkonsentrasi pada item-item yang telah diberikan konsumen pada kuadran ini.

\section{Kuadran II}

Produsen telah melakukan yang terbaik pada pelanggan atau konsumen sehingga hal yang perlu dilakukan adalah mempertahankan sikap, mutu dan proses kerja jika konsumen memberikan penilaian
Kuadran III

Antara konsumen dan produsen tidak terlalu memperhatikan penilaian atas kuadran ini sehingga dapat dijadikan prioritas terakhir atas upaya produsen untuk memperbaiki kinerjanya

Kuadran IV

Kelebihan kinerja dari prioritas atau dikatakan overskill.

Rata-rata kepentingan dan kepuasan pada dimensi bukti fisik (tangibles) dapat dilihat pada Tabel 4.6

Tabel 4.6 Rata-rata Kepentingan dan Kepuasan pada Dimensi Bukti Fisik (Tangibles)

\begin{tabular}{|c|c|c|c|}
\hline No & Atribut & Kepentingan & Kepuasan \\
\hline 1 & Lokasi hotel strategis & 4,14 & 3,66 \\
\hline 2 & Keadaan kamar hotel (bersih, nyaman, luas) & 4,02 & 3,20 \\
\hline 3 & Toilet kamar hotel (bersih, nyaman, wangi) & 3,86 & 3,16 \\
\hline 4 & Fasilitas yang ada di kamar hotel (TV, AC, kasur, selimut, WIFI) & 3,72 & 3,48 \\
\hline 5 & Tempat parkir luas & 3,74 & 2,30 \\
\hline 6 & Penampilan karyawan (rapi, sopan, seragam, formal) & 3,76 & 3,34 \\
\hline 7 & Penampilan manager (rapi, sopan) & 3,46 & 3,08 \\
\hline 8 & Tersedia kendaraan di hotel (mobil rental) & 3,70 & 2,30 \\
\hline \multicolumn{2}{|r|}{ Mean } & 3,8 & 3,1 \\
\hline
\end{tabular}




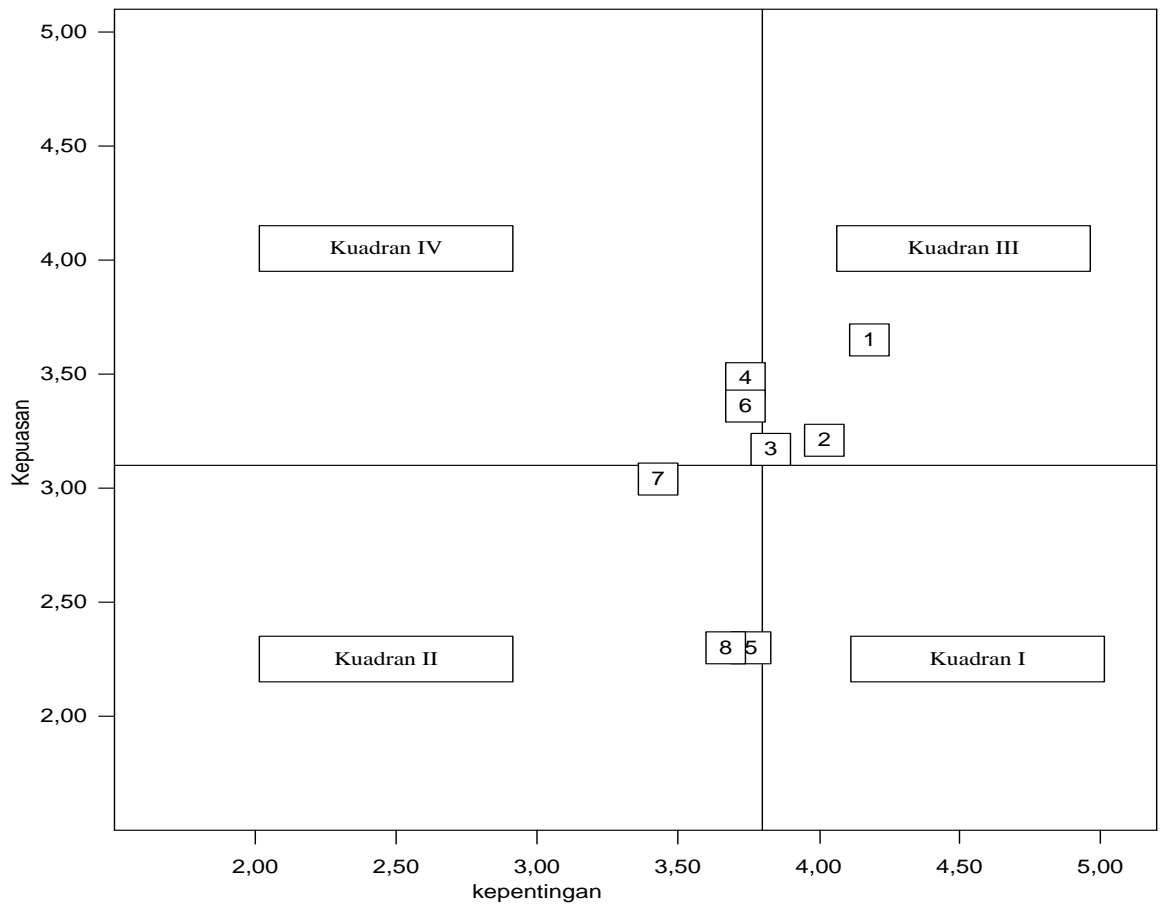

Gambar 4.2 Diagram Kartesius Dimensi Butki Fisik (Tangibles)

Rata-rata kepentingan dan kepuasan pada dimensi kehandalan (reliability) dapat dilihat pada Tabel 4.7

Tabel 4.7 Rata-rata Kepentingan Dan Kepuasan Pada Dimensi Kehandalan (Reliability)

\begin{tabular}{|c|c|c|c|}
\hline No. & Atribut & Kepentingan & Kepuasan \\
\hline 1 & Ketepatan waktu pelayanan & 4,04 & 3,34 \\
\hline \multicolumn{2}{|c|}{ Mean } & 4,04 & 3,34 \\
\hline
\end{tabular}

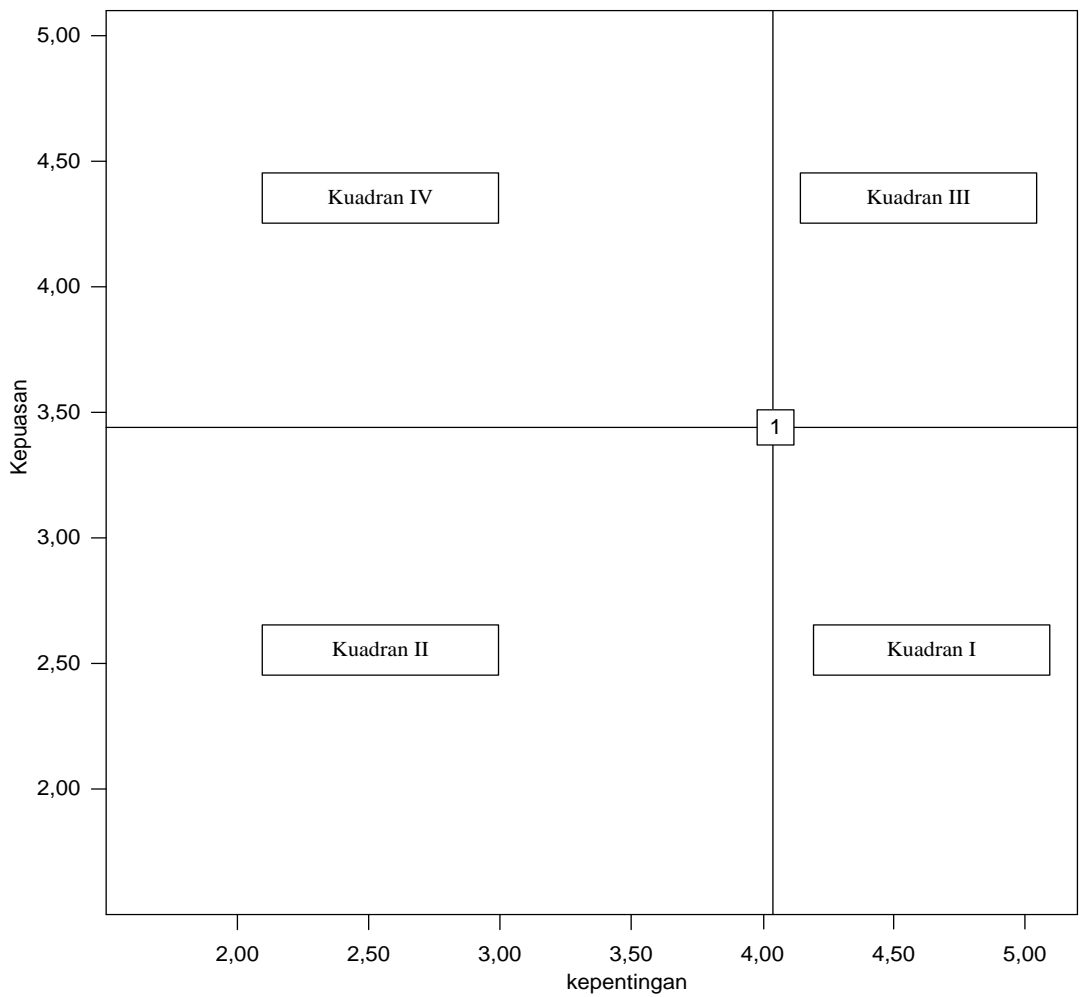

Gambar 4.3 Diagram Kartesius Dimensi Kehandalan (Reliability) 
Rata-rata kepentingan dan kepuasan pada dimensi daya tanggap (responssivness) dapat dilihat pada Tabel 4.8

Tabel 4.8 Rata-rata Kepentingan dan Kepuasan pada Dimensi Daya Tanggap (Responssivness)

\begin{tabular}{|c|l|c|c|}
\hline No. & Atribut & Kepentingan & Kepuasan \\
\hline 1 & Kecepatan karyawan dalam melayani pelanggan & 4,10 & 3,52 \\
\hline 2 & Manager mengatasi keluhan pelanggan dengan baik & 3,76 & 3,16 \\
\hline \multicolumn{2}{|c|}{ Mean } & 3,93 & 3,34 \\
\hline
\end{tabular}

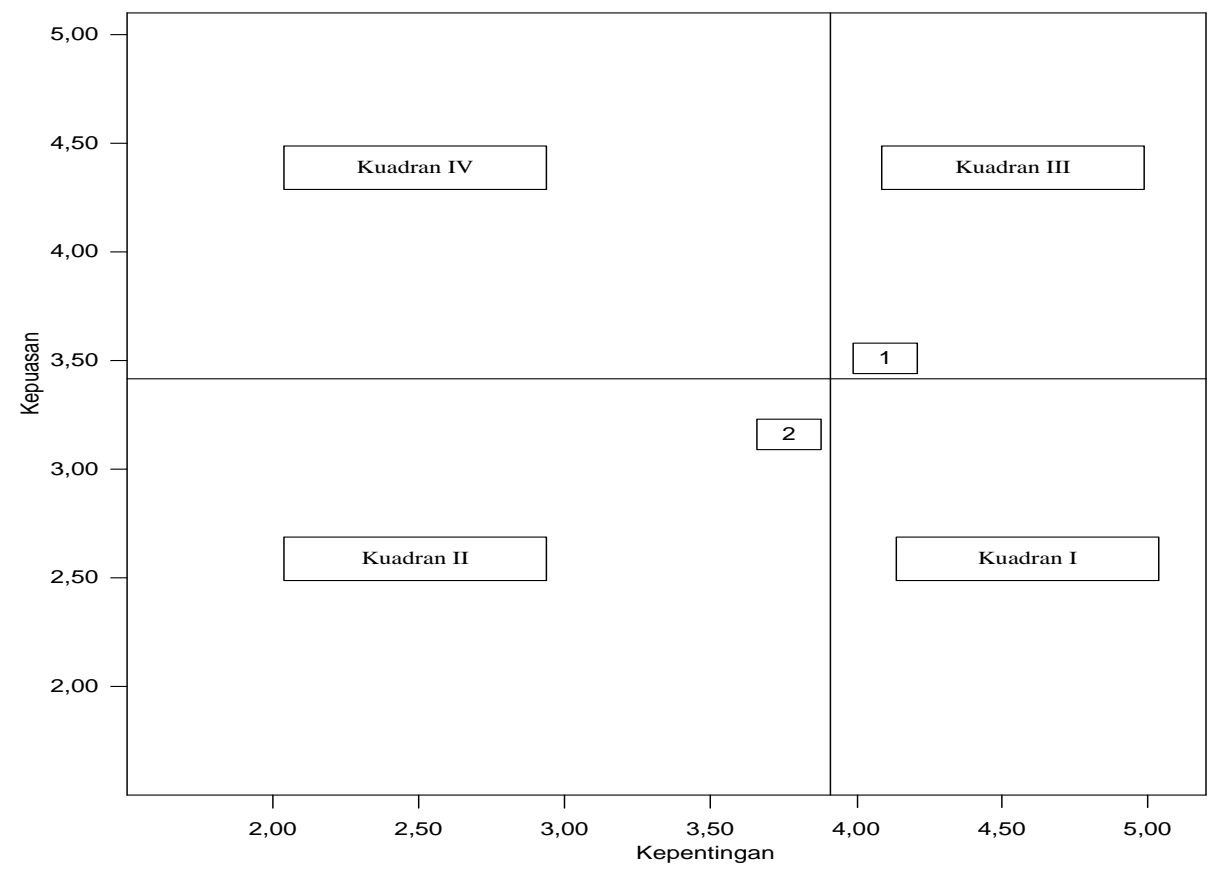

Gambar 4.4 Diagram Kartesius Dimensi Daya Tanggap (Responsiveness)

Rata-rata kepentingan dan kepuasan pada dimensi jaminan (assurance) dapat dilihat pada Tabel 4.9 Tabel 4.9 Rata-rata Kepentingan dan Kepuasan pada Dimensi Jaminan (Assurance)

\begin{tabular}{|c|c|c|c|}
\hline No. & Atribut & Kepentingan & Kepuasan \\
\hline 1 & Adanya pihak keamanan/security (satpam) & 3,86 & 3,72 \\
\hline \multicolumn{2}{|c|}{ Mean } & 3,86 & 3,72 \\
\hline
\end{tabular}

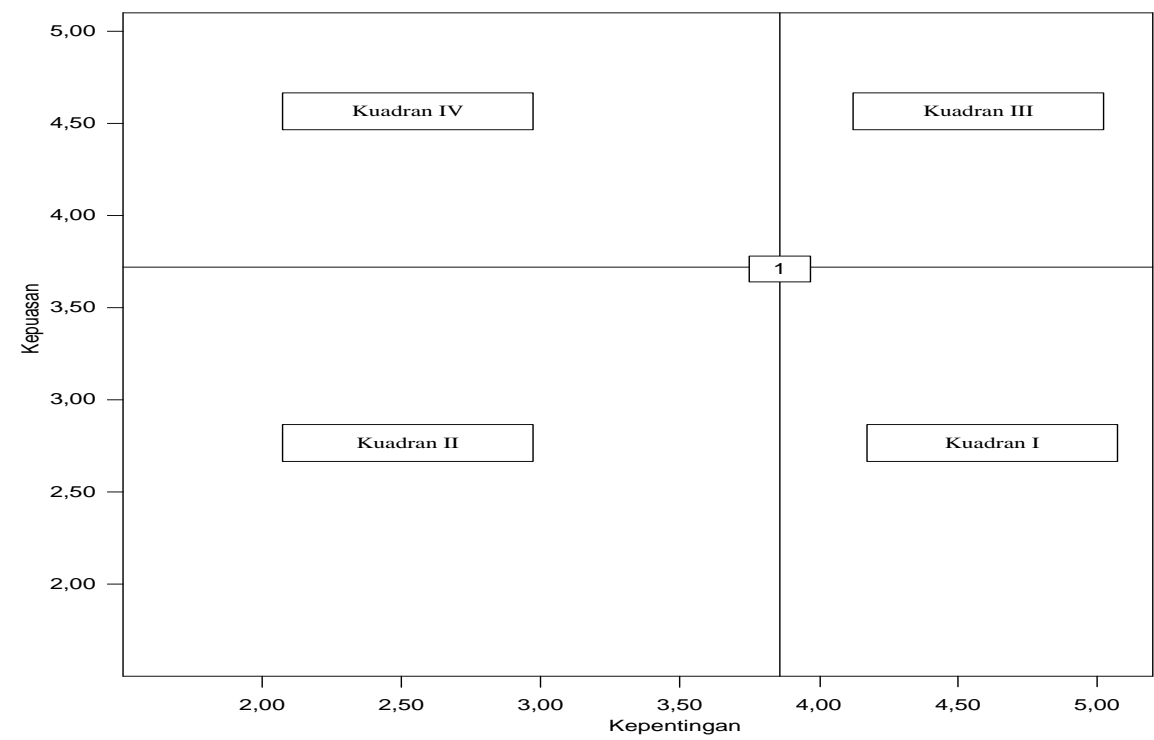

Gambar 4.5 Diagram Kartesius Dimensi Jaminan (Assurance) 
Rata-rata kepentingan dan kepuasan pada empati (emphaty) dapat dilihat pada Tabel 4.10

Tabel 4.10 Rata-rata Kepentingan dan Kepuasan pada Empati (Emphaty)

\begin{tabular}{|c|l|c|c|}
\hline No & \multicolumn{1}{|c|}{ Atribut } & Kepentingan & Kepuasan \\
\hline 1 & Keramahan karyawan terhadap pelanggan & 4,42 & 3,46 \\
\hline 2 & Ketersediaan waktu karyawan dalam mendengar keluhan pelanggan & 4,04 & 3,32 \\
\hline 3 & Karyawan dapat berkomunikasi dengan baik & 3,90 & 3,52 \\
\hline \multicolumn{2}{|c|}{ Mean } & 4,12 & 3,43 \\
\hline
\end{tabular}

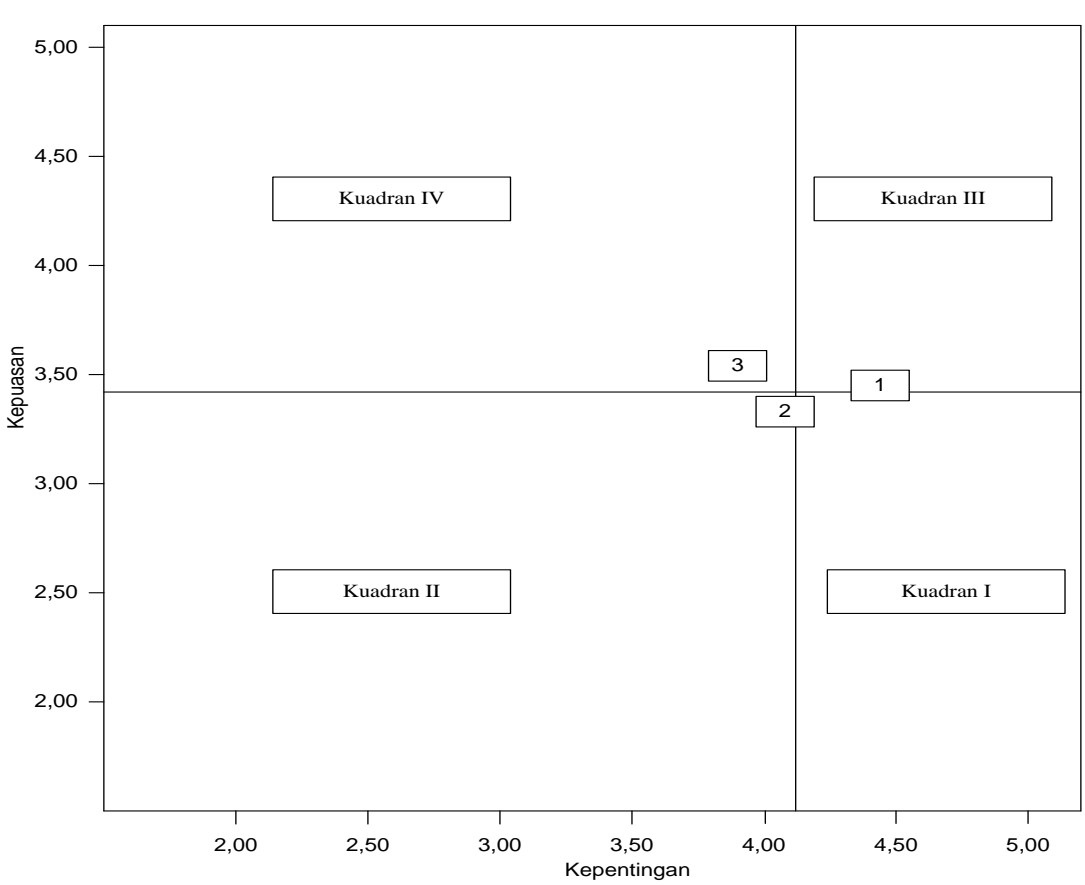

Gambar 4.6 Diagram Kartesius Dimensi Empati (Emphaty)

Rata-rata kepentingan dan kepuasan pada dimensi kualitas layanan dapat dilihat pada Tabel 4.11

Tabel 4.11 Rata-rata Kepentingan dan Kepuasan pada Dimensi Kualitas Layanan

\begin{tabular}{|c|l|c|c|}
\hline No. & \multicolumn{1}{|c|}{ Dimensi } & Kepentingan & Kepuasan \\
\hline 1 & Bukti Fisik (Tangibles) & 3,8 & 3,06 \\
\hline 2 & Kehandalan (Reliability) & 4,04 & 3,34 \\
\hline 3 & Daya Tanggap (Responssivness) & 3,93 & 3,34 \\
\hline 4 & Jaminan (Assurance) & 3,86 & 3,72 \\
\hline 5 & Empati (Emphaty) & 4,06 & 3,43 \\
\hline \multicolumn{2}{|c|}{ Mean } & 3,95 & 3,38 \\
\hline
\end{tabular}

\subsection{Analisis Hasil}

4.3.1 Analisis pada masing-masing dimensi 1) Nilai kepentingan/harapan.

Hasil penelitian yang dipaparkan pada tabel 4.5 memperlihatkan bahwa nilai kepentingan/harapan terbesar adalah pada dimensi empati (emphaty) $(4,06)$, nilai kepentingan/harapan terkecil adalah pada dimensi bukti fisik (tangibles) $(3,8)$, sedangkan nilai kepentingan/harapan rata-rata untuk tiap dimensi adalah $(3,95)$. Hal ini menunjukkan bahwa rata-rata responden lebih menaruh kepentingan/harapan pada dimensi empati (emphaty) dibandingkan dengan dimensidimensi yang lain. Hal ini juga menunjukkan bahwa empati atau memahami kebutuhan para pelanggan lebih diprioritaskan oleh pihak Hotel Vidi 2.

2) Nilai kepuasan/persepsi

Hasil penelitian yang dipaparkan pada tabel 4.5 memperlihatkan bahwa nilai kepuasan/persepsi terbesar adalah pada dimensi jaminan (assurance) (3,72), nilai kepuasan/persepsi terkecil adalah dimensi bukti fisik (tangibles) $(3,065)$, sedangkan nilai kepuasan/persepsi ratarata untuk tiap dimensi adalah $(3,38)$. $\mathrm{H}$ 
menunjukkan bahwa rata-rata responden menilai kepuasan/persepsi pada dimensi jaminan (assurance) lebih memuaskan dibanding dimensi-dimensi lainnya. Pihak Hotel
Vidi 2 lebih memperhatikan atribut jaminan petugas keamanan (satpam) terhadap kebutuhan keamanan pelanggan.

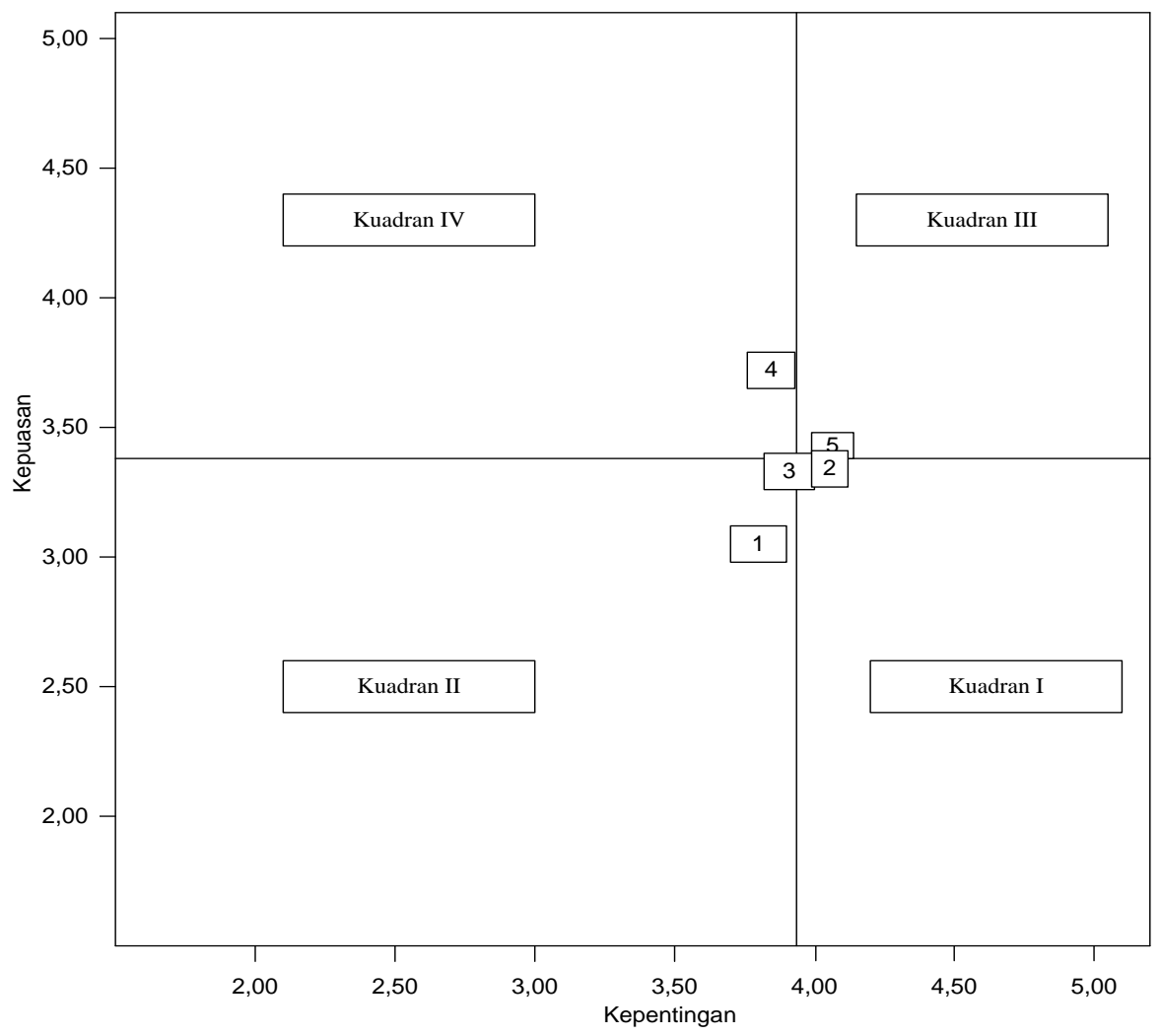

Gambar 4.7 Diagram Kartesius Dimensi Kualitas Pelayanan

3) Nilai gap/kesenjangan

Hasil penelitian yang dipaparkan pada tabel 4.5 memperlihatkan bahwa nilai gap/kesenjangan terbesar adalah dimensi bukti fisik (tangible) $(-0,735)$, nilai gap/kesenjangan terkecil adalah dimensi jaminan (assurance) $\quad(-0,14)$, sedangkan nilai gap/kesenjangan rata-rata untuk tiap dimensi adalah $(-0,57)$. Hal ini menunjukkan bahwa rata-rata responden merasakan tingkat kesenjangan yang lebih tinggi pada dimensi bukti fisik (tangible) dibandingkan dengan dimensi-dimensi lainnya. Urutan nilai gap/kesenjangan yang memiliki nilai gap/kesenjangan terbesar hingga terkecil adalah dimensi bukti fisik (tangible) $(-0,735)$, dimensi kehandalan (reliability) $(-0,7)$, dimensi empati (emphaty) $(-0,687)$, dimensi daya tanggap (responsiveness) $(-0,59)$, dan dimensi jaminan (assurance) $(-0,14)$.

\subsubsection{Analisis kualitas}

Kualitas merupakan perbandingan antara nilai kepentingan/harapan dan kepuasan/persepsi.
Dari hasil penelitian ditunjukkan bahwa kualitas masing-masing dimensi hampir berimbang. Walaupun nilai kualitas (Q) semua dimensi masih di bawah 1 , namun kualitas pelayanan untuk Hotel Vidi 2 dalam hal ini dikatakan cukup baik. Hanya saja memang perlu dilakukan usaha-usaha peningkatan yang lebih terarah dari pihak Hotel Vidi 2 agar kualitas pelayanan semakin baik.

4.3.3 Analisis diagram kartesius seluruh atribut Dalam perhitungan rata-rata skor kepentingan dan skor kepuasan untuk semua atribut kebutuhan pelanggan, diperoleh nilai mean dari skor kepentingan $(\mathrm{X})$ dan skor kepuasan $(\mathrm{Y})$ sebesar 3,89 dan 3,24 yang nantinya akan dijadikan batas kuadran dalam diagram kartesius.

Pada Gambar 4.1 dapat dilihat bahwa atribut yang berada pada kuadran I, II, III, dan IV yaitu: 1) Kuadran $I$

Atribut-atribut yang masuk dalam kuadran I yaitu: 
- Keadaan kamar hotel (bersih, nyaman, luas)

Hal ini menunjukkan bahwa atribut yang berada dalam kuadran I tersebut menjadi prioritas utama bagi pihak Hotel Vidi 2 untuk lebih dikembangkan lagi. Karena dilihat dari tingkat kepentingan/harapan memiliki nilai yang tinggi namun tidak didukung dengan nilai kepuasan/persepsi yang tinggi, sehingga perlu adanya perbaikan agar kepuasan/persepsi dapat meningkat. Perbaikan dapat dilakukan dengan meningkatkan kinerja perusahaan yang dapat mendukung terciptanya kebutuhan pelanggan, sehingga kepuasan pelanggan dapat meningkat karena apa yang mereka butuhkan telah mereka dapatkan.

2) Kuadran II

Atribut-atribut yang masuk dalam kuadran II yaitu:

- Toilet kamar hotel (bersih, nyaman, wangi)

- Tempat parkir luas

- Penampilan manager (rapi, sopan)

- Tersedia kendaraan di hotel (mobil rental)

- Manager mengatasi keluhan dengan baik

Hal ini menunjukkan bahwa atribut-atribut yang berada dalam kuadran II tersebut menjadi prioritas rendah bagi pihak Hotel Vidi 2 untuk dilakukan perbaikan, karena memiliki nilai kepentingan dan kepuasan yang sama-sama rendah. Keberadaan atribut-atribut ini dianggap tidak mempengaruhi tingkat kepuasan pelanggan, termasuk atribut-atribut yang kurang dibutuhkan oleh pelanggan dan pelaksanaan kinerjanya dianggap biasa saja atau kurang memuaskan. Jadi akan sia-sia jika dilakukan perbaikan dengan kepentingan/harapan dapat meningkatkan kepuasan pelaggan Hotel Vidi 2 namun pelanggan sendiri tidak menganggap atribut-atribut tersebut sebagai sesuatu yang penting.

3) Kuadran III

Atribut-atribut yang masuk dalam kuadran III yaitu:

- Lokasi hotel strategis

- Ketepatan waktu pelayanan

- Kecepatan karyawan dalam dalam melayani pelanggan

- Keramahan karyawan terhadap terhadap pelanggan

- Ketersediaan waktu karyawan dalam mendengar keluhan pelanggan

Hal ini menunjukkan bahwa atribut-atribut yang berada dalam kuadran III tersebut harus dipertahankan prestasinya oleh Hotel Vidi 2, Ditinjau dari segi kepuasan, pelanggan Hotel
Vidi 2 sudah merasakan kepuasan akan pelayanan yang diberikan pihak hotel, oleh karena itu hal ini harus tetap dipertahankan agar pelanggan dapat terus merasakan kepuasan sehingga tidak beralih ke pesaing.

4) Kuadran IV

Atribut-atribut yang masuk dalam kuadran IV yaitu:

- Fasilitas yang ada dikamar hotel (TV, AC, kasur, selimut, WIFI)

- Penampilan karyawan (rapi, sopan, seragam, formal)

- Adanya pihak keamanan/security (satpam)

- Karyawan dapat berkomunikasi dengan baik Hal ini menunjukkan bahwa atribut-atribut yang berada dalam kuadran IV tersebut dipandang terlalu berlebihan oleh pelanggan Hotel Vidi 2. Dikatakan berlebihan karena dilihat dari tingkat kepentingan/harapannya yang rendah namun dengan tingkat kepuasan/persepsinya yang tinggi. Sehingga pihak hotel dapat melakukan pengurangan pelayanan kinerjanya dari atributatribut tersebut dengan tujuan mengurangi sedikit pengeluaran, asalkan pelanggan masih bisa merasakan kepuasan di atas pesaing.

\section{KESIMPULAN DAN SARAN}

\subsection{Kesimpulan}

Berdasarkan analisis hasil maka dapat diambil kesimpulan sebagai berikut:

1) Nilai kualitas pelayanan (Q) Hotel Vidi 2 semuanya masih di bawah 1 , namun dalam hal ini dikatakan cukup baik. Tetapi masih perlu dilakukan usaha-usaha peningkatan yang lebih terarah dari pihak Hotel Vidi 2 supaya kualitas pelayanannya semakin meningkat. Dimensi bukti fisik (tangible) merupakan dimensi yang memiliki nilai kualitas terkecil yaitu sebesar 0,806 , penilaian tersebut. Nilai kualitas terbesar terdapat pada dimensi jaminan (Assurance) yaitu sebesar 0,964. Hal ini dapat dilihat dari sifat dapat dipercaya yang dimiliki para pegawai, bebas dari bahaya, resiko, atau keraguraguan.

2) Terdapat satu atribut, yakni keadaan kamar hotel yang berada di kuadran I, yang artinya perlu adanya peningkatan kualitas terhadap atribut tersebut. Oleh karenanya, penulis menyarankan agar pihak manajemen Hotel Vidi 2 mengadakan proyek renovasi kamar Hotel Vidi 2 untuk memenuhi tingkat kepuasan pelanggan, hal yang di usulkan peneliti berikutnya manajemen dari Hotel Vidi 2 bisa menggunakan pihak ketiga dalam kegintan tersebut. 


\subsection{Saran}

Bedasarkan hasil penelitian, ada beberapa hal yang bisa dijadikan bahan pertimbangan untuk penelitian selanjutnya, berikut pertimbangannya:

1) Penelitian selanjutnya diharapkan dapat menggunakan metode lain untuk peningkatan kualitas pelayanan pelanggan.

2) Penelitian selanjutnya diharapkan dapat mempertimbangkan dan menambahkan atributatribut lain yang belum tertulis dalam penelitian ini.

\section{DAFTAR PUSTAKA}

Azwar, S., 2004, Reliabilitas dan Validitas. Yogyakarta: Pustaka Pelajar Offset

Brandt, D. R., 2000, An “Outside In” Approach to Determining Customer-Driven Priorities for Improvement and Innovation, White Paper Series, Vol. 2.

Ariani, D. W., (2003). Pengendalian Kualitas Statistik (Pendekatan Kualitatif Dalam Manajemen Kualitas). Yogyakarta : Andi Offset.

Kotler, P., 1994, Manajemen Pemasaran, Edisi Keenam, Penerbit Erlangga, Jakarta.

Kusuma, R. A., 2009, Perumusan Blue Ocean Strategy Dengan Menggunakan Pendekatan Metode Servqual Untuk Meningkatkan Kepuasan Pelanggan. Yogyakarta: Universitas Islam Indonesia.

Lawson, F., 1976, Hotels, Motels and Condominiums: Design, Planning and Maintenance.

Parasuraman, A. Zeithaml V. A, and Berry L.L., 1985. Conceptual model of service quality and its implications for future research. Journal of Marketing, Vol. 49, 41-50.
Parasuraman, A., 1988, A Conceptual Model of Service Quality and its Implications For Future Research, Journal of Marketing, Vol.49.

Parasuraman, A., 1993, Delivering Quality Service: Balancing Customer Perceptions and Expectations (Free Press:New York).

Rangkuti, F., 2002, Measuring Costumer Satisfaction, Teknik Mengukur dan Strategi Meningkatkan Kepuasan Pelanggan Plus Analisis Kasus PLN-JP, PT. Gramedia Pustaka Utama, Jakarta.

Rumita, R., 2014, Analisis Kepuasan Mahasiswa dan Usulan Peningkatan Kualitas Jasa Pelayanan Administrasi Kemahasiswaan Dengan Menggunakan Model SERVQUAL, IPA, dan QFD. Semarang: UNDIP.

Supranto, J., 2001, Pengukuran Tingkat Kepuasan Pelanggan Untuk Menaikan Pangsa Pasar, PT Rineka Cipta, Jakarta.

Tjiptono, F., 1996, Manajemen Jasa, Andi, Yogyakarta.

Tjiptono, F., 2000, Strategi Pemasaran, Andi Offset, Yogyakarta.

Umar, H., 1997, Metodelogi Penelitian Aplikasi dalam Pemasaran. Jakarta: Gramedia.

Zeithaml, Parasuraman \& Berry., 1990, Delivering Quality Service : Balancing Costumer Perseptions and Expectations, The Free Press Collier Macmillan

Publihers - USA.

Zeithaml, V. A dan Bitner, M. J., 2004, Service Marketing- Integrating Customer Focus Across The Firm. Fifth Edition. Mc GrawHill Companiees. Inc 